Authors: Mathieu Ardyna ${ }^{1}$, Hervé Claustre ${ }^{1}$, Jean-Baptiste Sallée ${ }^{2}$, Francesco

\title{
Delineating environmental control of phytoplankton biomass and phenology in the Southern Ocean
}

\author{
d'Ovidio $^{2}$, Bernard Gentili ${ }^{1}$, Gert van Dijken ${ }^{3}$, Fabrizio D'Ortenzio ${ }^{1}$, Kevin Arrigo ${ }^{3}$
}

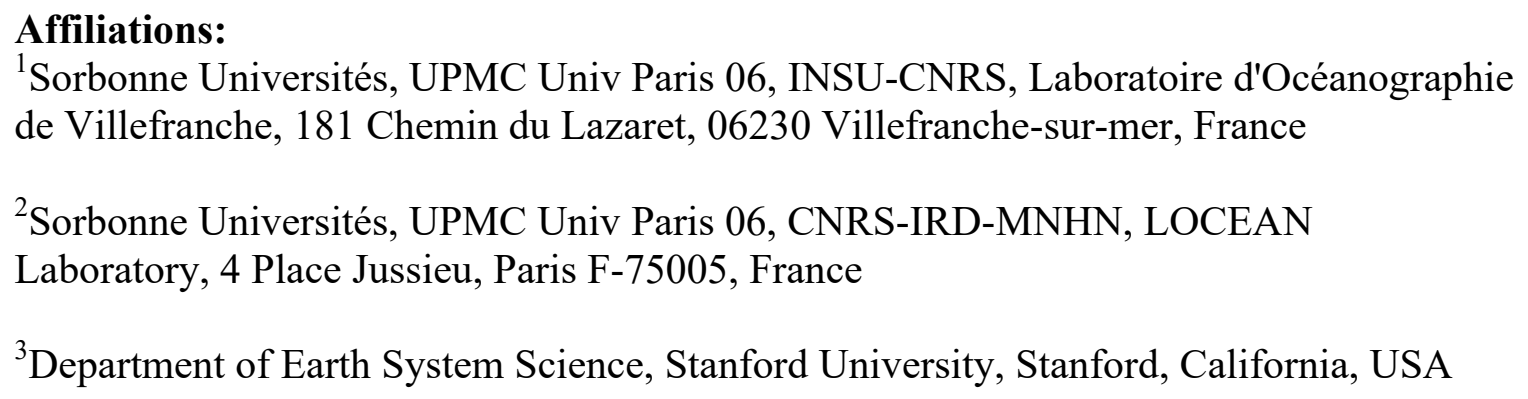

Main point \#1: Phytoplankton phenology and biomass are mostly organized in the Southern Ocean at a large latitudinal scale and a regional scale.

Main point \#2: The timing of bloom occurrence appears tightly linked to the seasonal cycle in irradiance, with some exceptions in specific light-limited regimes.

Main point \#3: Zonal asymmetries in regional-scale phytoplankton biomass are mainly driven by local advective and iron supply processes.

Running head (40 characters max): Phytoplankton dynamics in the SO

Keywords: Phytoplankton ecology, Phytoplankton phenology, Biological pump, Climate Change, Southern Ocean, Remote sensing.

*Correspondence to: Mathieu.Ardyna@obs-vlfr.fr.

45 To be submitted to Geophysical Research Letters 


\section{Abstract}

47 The Southern Ocean (SO), an area highly sensitive to climate change, is currently experiencing 48 rapid warming and freshening. Such drastic physical changes might significantly alter the SO's

49 biological pump. For more accurate predictions of the possible evolution of this pump, a better 50 understanding of the environmental factors controlling SO phytoplankton dynamics is needed.

51 Here we present a satellite-based study deciphering the complex environmental control of 52 phytoplankton biomass (PB) and phenology $(\mathrm{PH}$; timing and magnitude of phytoplankton 53 blooms) in the SO. We reveal that $\mathrm{PH}$ and $\mathrm{PB}$ are mostly organized in SO at two scales: a large 54 latitudinal scale, and a regional scale. Latitudinally, a clear gradient in the timing of bloom 55 occurrence appears tightly linked to the seasonal cycle in irradiance, with some exceptions in 56 specific light-limited regimes (i.e. well-mixed areas). Superimposed on this latitudinal scale, 57 zonal asymmetries, up to three orders of magnitude, in regional-scale PB are mainly driven by 58 local advective and iron supply processes. These findings provide a global understanding of PB 59 and $\mathrm{PH}$ in $\mathrm{SO}$, which is of fundamental interest for identifying and explaining ongoing changes 60 as well as predicting future changes in the SO biological pump.

\section{1. Introduction}

63 The Southern Ocean (SO) plays a key role in the global carbon cycle, absorbing $40 \%$ of the

64 total oceanic inventory of anthropogenic $\mathrm{CO}_{2}$ [Khatiwala et al., 2009]. However, current and 65 predicted changes in ocean circulation and hydrology associated with climate variability might 66 impact the efficiency of the SO carbon sink, although the extent of such changes and their

67 specific impact on the biological pump are still vigorously debated [Landschützer et al., 2015; Le

68 Quéré et al., 2010; Munro et al., 2015]. Such debate cannot advance without a better 
69 understanding of the factors that shape the complex biogeography of the SO, and what controls

70 their time-scale of variability (i.e. daily, seasonal to decadal).

71 Delimiting marine bio-regions has proven highly valuable for disentangling multiple

72 limiting growth factors affecting the efficiency of the biological pump [Longhurst, 2007]

73 mediated by both $\mathrm{PB}$ and $\mathrm{PH}$, and for ultimately underlining effects of climate change such as

74 areal changes in trophic regime [Polovina et al., 2008] or in fisheries stock and species

75 [Fossheim et al., 2015]. Changes in PB profoundly alter the efficiency of the biological pump,

76 thereby modulating energy transfer to upper trophic levels and carbon export to deep water

77 [Legendre and Rassoulzadegan, 1995]. Changes in PH may also have important consequences

78 for the marine food web, due to potential mismatch between primary and secondary producers

79 and apex predators [Ardyna et al., 2014; Edwards and Richardson, 2004], and for the carbon

80 cycle through export of unexploited carbon aggregates to the deep ocean [Dall'Olmo et al., $812016]$.

82 The efficiency of the SO's biological pump is strongly associated with phytoplankton

83 biomass $(\mathrm{PB})$ and its phenology $(\mathrm{PH})$, which themselves are mediated by nutrient availability

84 (e.g. mainly iron, and/or possibly nitrate and silicic acid), light, temperature and mortality factors

85 [Behrenfeld and Boss, 2014; Boyd, 2002]. These factors are essentially controlled by vertical

86 mixing, advection, seasonal fluctuations in solar irradiance, and the extent and typology of sea-

87 ice cover. As a result, a variety of patterns of net primary production (NPP) are found in the SO

88 [Arrigo et al., 2008], with their own associated phytoplankton species succession, stock, and

89 distribution [Quéguiner, 2013]. Delineating the interplay of environmental forcing on PB and PH

90 remains challenging and requires novel approaches, which are available through satellite-derived

91 observations. Using these integrative and multidisciplinary approaches (i.e. satellite-derived 
92 ocean color and altimetry, Argo floats, lagrangian modeling and biogeographic-derived

93 analysis), we provide here a global understanding of the phytoplankton biomass and phenology

94 in a potentially changing SO.

\section{2. Material and methods}

\section{$\underline{2.1 \text { Satellite-derived, climatological and modeling products }}$}

Satellite-derived Level-3 data sets of chlorophyll-a concentration ( $\operatorname{chl} a ; \mathrm{mg} \mathrm{m}^{-3}$ ) and

98 photosynthetically available radiation (PAR; $\mathrm{E} \mathrm{m}^{-2} \mathrm{~d}^{-1}$ ) were obtained from the European Space

99 Agency's GlobColour project (htp://www.globcolour.info). Eight-day composite chl $a$

100 concentrations using standard Case 1 water algorithms were used (i.e. OC4v5 for SeaWIFS,

101 OC4Me for MERIS and OC3v5 for MODIS/VIIRS sensors; see O'Reilly et al. [2000] and

102 Maritorena et al. [2010] for details). The climatological annual net primary production (NPP)

103 was derived from the adapted-SO NPP model of Arrigo et al. [2008]. A detailed description of

104 the NPP model can be found in the supporting information [Dobson and Smith, 1988; Gregg and

105 Carder, 1990; Markus, 1999]. The climatologies of mixed layer depth and bathymetry were

106 extracted respectively from Pellichero et al. [2016] and the GEBCO, version 2014 (General

107 Bathymetric Chart of the Oceans; http://www.gebco.net). The climatology of the length of the

108 sea-ice cover was derived from the Special Sensor Microwave Imager (SSMI; 1998-2002) and

109 the Advanced Microwave Scanning Radiometer - Earth Observing System (AMSR-E; 2002-

110 2014) sensors, and made available by National Snow and Ice Data Center (NSIDC;

111 https://nsidc.org). The locations of the major fronts (i.e. the Subantarctic Front SAF, the 112 Antarctic Polar Front APF, the Southern Antarctic Circumpolar Current (ACC) Front SACCF

113 and the Southern Boundary of the ACC SBdy, following Swart et al. [2010]) were determined

114 based on the Maps of Absolute Dynamic Topography (MADT) product from CLS/AVISO. The 
115 Lagrangian model of horizontal dispersion of iron fluxes used also altimeter products produced

116 by CLS/AVISO, with support from the CNES (Centre National d'Etudes Spatiales;

117 http://www.aviso.altimetry.fr/duacs/).

118 2.2. Clustering K-means method

119 The bio-regions were defined here using a cluster K-means analysis (see the SI for more 120 details), previously applied successfully in the Mediterranean Sea [D'Ortenzio and Ribera 121 d'Alcalà, 2009; Mayot et al., 2016], in the North Atlantic [Lacour et al., 2015] and at the global 122 scale [D'Ortenzio et al., 2012]. The analysis was performed on climatological and normalized 123 annual chl $a$ cycle, in order to statistically organize the GLOBcolour time series (1998-2014) 124 and to create clusters representing regions of similarity (i.e. annual $\operatorname{chl} a$ cycles). To maintain 125 consistency in the seasonal data availability throughout the study area, the period study covers 126 the period from September to March (as referred here to "annual"). This technique regroups 127 pixels with seasonal cycles shapes - i.e. similar phenologies. A single characteristic seasonal 128 cycle, that is statistically representative of the group as a whole, is then determined by 129 calculating the center (average cycle) within each group or cluster. Each group representative of 130 a characteristic seasonal cycle constitutes a phenological characteristic regime. A more detailed 131 discussion of the cluster K-means analysis can be found in the supporting information [Devred et 132 al., 2007; Hartigan and Wong, 1979; IOCCG, 2009; Lund and Li, 2009; Milligan and Cooper, $1331985]$

134 A one-way analysis of variance by ranks (Kruskal-Wallis H test; Zar [2010]) was 135 performed to test whether eco-regions differed in their biological characteristics (i.e. annual 136 mean chlorophyll $a$ concentration, seasonality and timing of bloom). A significant result of the 137 Kruskal-Wallis $\mathrm{H}$ test implies that at least one eco-region differs from all others. 
In order to estimate iron delivery due to horizontal stirring, we use an advection scheme

140 based on altimetry, extending to the Southern Ocean a Lagrangian model used for predicting the

141 development of the Kerguelen phytoplanktonic plume [d'Ovidio et al., 2015]. The model has

142 been extensively calibrated and validated in the Crozet and Kerguelen regions by integrating

143 satellite data (altimetry and ocean color), lithogenic isotopes, iron measurements, and drifters

144 [d'Ovidio et al., 2015; Sanial et al., 2014; Sanial et al., 2015]. The main characteristics of the

145 model were resumed here and we refer to d'Ovidio et al. [2015] for the full description of the

146 model. The model seeds each open ocean location with a particle and finds the particle's most

147 recent contact with a shallow bathymetry by a back-trajectory issued from altimetry data. It

148 provides the time and the position at which the contact took place. An exponential scavenging

149 relation (with a time constant based on in situ iron data from the KEOPS2 cruise) is used to

150 estimate the decreasing of bio-available iron along the trajectory from the time of the contact

151 with the potential iron source to the current position. Here, the model was applied to the entire

152 Southern Ocean using a grid of $0.25^{\circ}$, a time window of 2004-2015 (one map every 4 days),

153 potential sources of iron in the bathymetric band shallower than $500 \mathrm{~m}$, and a diffusion term of $15440 \mathrm{~m}^{2} \mathrm{~s}^{-1}$.

\section{Results and discussion}

157 Based on satellite-derived observations, a large range of both annual mean chlorophyll $a$ 158 (chl $a)$ concentration and net primary production (NPP) $\left(>0.1 \mathrm{mg}\right.$ chl $a \mathrm{~m}^{-3} / 20 \mathrm{~g} \mathrm{C} \mathrm{m}^{-2} \mathrm{y}^{-1}$ to 159 more than $2 \mathrm{mg}$ chl $a \mathrm{~m}^{-3} / 400 \mathrm{~g} \mathrm{C} \mathrm{m}^{-2} \mathrm{y}^{-1}$, respectively) were observed across the SO. It occurs 160 at a variety of scales, including the latitudinal and the regional (i.e. Indian, Pacific and Atlantic; 
161 Fig. 1a) scales in the SO. The annual mean chl $a$ concentration is associated with the amplitude

162 of its seasonal cycle (Fig. 1a\&c). In contrast, the timing of blooms (i.e. the maximum of the

163 annual chlorophyll cycles, Fig. 1d) appears entirely decoupled from both large-scale patterns in

164 annual chl $a$ concentration and its seasonality (Fig. 1c), hence revealing a complex organization 165 of phenological patterns of the $\operatorname{chl} a$ annual cycle.

166 Here, we disentangle the spatial complexity of chl $a$ seasonal cycle using a K-mean 167 clustering method [D'Ortenzio et al., 2012] with the goal of defining distinct bio-regions with 168 similar large-scale patterns in PH (Fig. 2). In brief, this technique statistically gathers regions 169 that exhibit similarly shaped seasonal chl $a$ cycles (see the section 2.2 for more details). The 170 seven distinct bio-regions so identified are distributed along a latitudinal gradient (Fig. 3a). At 171 temperate latitudes, two bio-regions (i.e. 1 and 2) exhibit an early bloom in October. Moving 172 south to $45-63^{\circ} \mathrm{S}$, two other bio-regions (i.e. 4 and 5) display an annual chl $a$ cycle with a 173 delayed bloom in November/December. Finally, near the Antarctic continental shelf $\left(<63^{\circ} \mathrm{S}\right)$, 174 the dominant bio-regions $6 \& 7$ were characterized by a late bloom in January/February. 175 Interestingly, one bio-region (i.e. 3) differs drastically from the general phenological trend of a 176 delayed bloom moving from subtropical to polar latitudes, having a late bloom at a moderate 177 latitude $\left(\approx 43^{\circ} \mathrm{S}\right.$, Fig. $\left.2 \& 3 \mathrm{~d}\right)$. Furthermore, the co-existence of bio-regions at a same latitude 178 indicates variations in the seasonality of the annual chl $a$ cycle (e.g., $1 \& 2,4 \& 5$ and $6 \& 7$ ) 179 which are related to distinct levels of PB (Figs 3b-c).

180 From temperate to high latitudes, the latitudinal gradient in bloom timing clearly follows 181 changes in light regime (expressed as the annual mean photosynthetically available radiation in 182 the double boxplot; Fig. 4a). The unique bio-region (i.e., 3), characterized by a paradoxically late 183 bloom with respect to the timing of light availability, is mainly located in the vicinity of the 
184 Antarctic Circumpolar Current. Interestingly, this region corresponds to the highest Southern

185 Ocean wind stress and depth of the mixed layer (see SI, Fig. S1). Deep mixed-layers likely

186 impose severe light limitation to phytoplankton growth in spring, hence delaying the bloom later

187 in season. Close to the Antarctic shelf, as shown locally in the western Antarctic Peninsula

188 [Venables et al., 2013], the timing of the bloom (Fig. 2) was not related to winter sea-ice extent

189 but more to the seasonal cycle of irradiance.

190 To address the potential causes of regional-scale variability in PB (Fig. 1a), we hypothesize

191 that iron availability represents its first order driver [Hutchins and Boyd, 2016]. Using integrative

192 and multidisciplinary approaches, we disentangle the impact of four important iron supply

193 mechanisms on PB. These surface-layer iron-sources are shallow plateaus $(<500 \mathrm{~m})$ which both

194 (i) locally recharge the surface-layer in iron [Arrigo et al., 2015; Graham et al., 2015] and (ii)

195 remotely recharge the surface layer by lateral advection of non-consumed iron [d'Ovidio et al.,

196 2015; Graham et al., 2015]; (iii) sea-ice, which recharges the surface as ice melts [Arrigo et al.,

197 2015; Lannuzel et al., 2016]; and (iv) vertical mixing through deep convection, which can

198 entrain iron from deep water [Tagliabue et al., 2014b]. Below, the potential impact of these four

199 likely iron-sources on the intensity of PB is investigated. Note that the Aeolian iron deposition

200 was not considered here as a major iron supply mechanism due to its intermittency and its

201 unclear role in regulating PB [Boyd et al., 2012; Cassar et al., 2007; Tagliabue et al., 2009;

202 Tagliabue et al., 2017].

203 Clearly, the highest PB $\left(>1.2 \mathrm{mg} \mathrm{m}^{-3}\right)$ are detected in shallow areas $(<500 \mathrm{~m})$, on 204 continental and island shelves where iron fluxes are expected to be significant [Boyd et al., 2012;

205 Tagliabue et al., 2014a]. Furthermore, we use a Lagrangian model based on altimetry in order to 206 track which water parcels have been recently in contact with a shallow area - and when - to 
207 assess the probable locations of some of the iron plumes downstream of these iron sources and to

208 estimate their loss of bio-available iron during advection by scavenging [d'Ovidio et al., 2015].

209 We find a well-defined decline in PB (from 0.8 to $0.3 \mathrm{mg} \mathrm{m}^{-3}$ ) with distance and time from the

210 most recent contact of the water parcel with a shallow area (Fig. 4b): the further away a water-

211 parcel is from the initial shallow area iron source, or the longer after a water-parcel has been

212 iron-enriched in shallow areas, the weaker is the PB signal. We note however that seamounts and

213 submerged plateaus do not enhance local or downstream PB, as already observed north of

214 Kerguelen plateau [Graham et al., 2015] (Figs. 1a\&4c), suggesting that not all shallow areas are

215 active and/or bioavailable iron sources. Close to the Antarctic shelf and coastal polynyas, the

216 potential role of the seasonal melting of sea-ice [Arrigo et al., 2015; Lannuzel et al., 2016] as

217 iron source is revealed with enhanced PB $\left(\approx 0.4 \mathrm{mg} \mathrm{m}^{-3}\right)$.

218 Moving away from potential iron delivery from shallow areas (either locally or

219 downstream) and from sea-ice, we investigated the possible role of mixed-layer depth on

220 regulating $\mathrm{PB}$. If deepening of the mixed layer in winter can recharge the surface layer in

221 nutrients (iron, but also nitrate and silicic acid in the temperate regimes) by deep convection, it

222 can also limit PB by reducing light availability for phytoplankton growth during the growing

223 season. Indeed, region of deep winter mixing in the Southern Ocean are mostly located directly

224 north of the ACC, where strong winds and isopycnal tilts, are associated with an season-wide

225 weak stratification, leading to deep winter mixed layer but also to relatively deep, compared to 226 their surrounding, spring and summer mixed-layers.

227 Our findings clearly translate this complex interplay between availability of nutrient and

228 light related to the winter mixed-layer depth. An increase in PB is observed with the deepening 229 of the winter mixed-layer until a maximum winter depth of about $150 \mathrm{~m}$. When the winter mixed 
230 layer becomes deeper, a decrease in PB is observed, likely resulting from a stronger light

231 limitation of phytoplankton growth during the growth season (Sep-Mar; on average, winter

232 mixed layer deeper than $150 \mathrm{~m}$ are associated to Sep-Mar mixed layer deeper than $110 \mathrm{~m}$ or so;

233 Fig $4 \mathrm{~b}$ ). We thus depict here a tipping winter MLD at $\sim 150 \mathrm{~m}$, which likely represents a shift

234 between an iron-limited to a light-limited environment. Such threshold in the MLD is certainly

235 dependent on the local structure of the iron profile [Tagliabue et al., 2014b]. Despite the HNLC

236 (High Nutrient Low Chlorophyll) nature of the Southern Ocean, an intermediate mixing mode

237 (i.e., with a winter MLD maximum from 120 to 200 meters) appears to enhance PB by supplying

238 an optimal combination of both light and nutrient requirements for phytoplankton growth. This

239 apparently modest effect of optimal mixing on PB may nevertheless have major implications due

240 to the large areal extension of those zones relying on the vertical mixing to support

241 phytoplankton iron requirements (Fig. 4c).

242 Deciphering the complexity of the SO's phytoplankton phenology and biomass is

243 particularly critical to assess how climate variability and change might regionally impact the

244 biological pump. Our results reveal two main scales of organization for both PB and PH, i.e. a

245 large latitudinal and a regional scale. Alterations of stratification that are expected with global

246 warming may modify light-mixing regimes, and thus potentially modulate the bloom timing.

247 However, since the phenology appears here to be strongly linked to the circumpolar seasonal

248 cycle in irradiance, we suppose that only drastic changes in stratification could significantly alter

249 bloom timing, and therefore the impact on the biological pump might be expected to be relatively

250 minor.

251 Concerning the fate of phytoplankton biomass in the changing SO, no particular changes at

252 local scale are expected in shallow bathymetry (i.e. where iron recharge from shallow plateaus 
$253(<500 \mathrm{~m})$ are not prone to be affected). Potential changes also likely to remain minor in 254 downstream transport from ACC, depending on whether the ACC has shifted locally in some 255 regions over the past decades according to climate model [Kim and Orsi, 2014; Sallée et al., 256 2008] but not others [Gille, 2014; Shao et al., 2015]. Even if ACC changes remain unclear under 257 next century climate change scenarios [Meijers et al., 2012], past studies indicate that if there is a 258 change, the expected position change should be small compared to the size of the bathymetry 259 structure it interacts with to give rise to ocean surface iron plumes.

260 The main uncertainties regarding the fate of PB thus remains linked to the role of the 261 mixed-layer depth and the sea-ice, which have a more direct response to climate variability and 262 change. Climate modes have direct regional impact on both sea-ice and mixed-layer depth 263 [Sallée et al., 2010; Simpkins et al., 2012]. In response to SAM and ENSO, sea-ice extends in 264 some regions and is reduced in others, which, according to our results, would have regional 265 impact on iron delivery and PB intensity. Similarly, SAM tends to deepen mixed-layer depth 266 regionally but shallows it in other regions. Under next century climate change, the response is 267 more regionally consistent, with an overall shallowing of the mixed-layer associated with 268 increased stratification (freshwater input from glacier and sea-ice, and increased heat forcing 269 from the atmosphere), and an overall reduction of sea-ice cover.

270 However, according to our findings, a shallowing (or deepening) of the mixed-layer is not 271 expected to translate to the same PB response everywhere (see SI, Fig. S2). Indeed, the response 272 would be state-dependent: a shallowing of a deep mixed-layer (typically deeper than $200 \mathrm{~m}$ ) 273 would result in an increase in PB, while a shallowing of an already relatively shallow mixed274 layer (typically less than $120 \mathrm{~m}$ ), would reduce PB. At the SO scale, a global shallowing of the 275 mixed-layer depth appears to have negative consequences on PB (loss of $\approx 0.3 \% \mathrm{~m}^{-1}$; see SI), 
276 mainly due to the areal increase of depleted-iron regions with less efficient vertical iron recharge.

277 Conversely, a positive response of PB (increase of $\approx 0.15 \% \mathrm{~m}^{-1}$; see SI) would be observed with

278 a global deepening of the mixed-layer until a critical threshold ( $+40 \mathrm{~m}$ compared to the actual

279 mixed-layer depth climatology), from which severe light limitation damps phytoplankton growth

280 and biomass. Given the more direct response of the MLD to climate variability and change in the

281 SO, these results highlight the crucial role of the local vertical mixing and the associated subtle

282 balance between light/nutrient availability on regulating PB in the majority of the HNLC areas of 283 the SO.

284

285 Acknowledgments

286 The GLOBcolour data were made available by the European Space Agency's GlobColour 287 project (http://www.globcolour.info). The altimetric data was provided by AVISO/CNES from 288 their website http://www.aviso.altimetry.fr/fr/. We gratefully acknowledge the whole OMTAB 289 team for constructive discussion on initial versions of the manuscript. We also thank Bernard 290 Quéguiner and an anonymous reviewer for constructive comments on the manuscript. M.A. 291 received a postdoctoral fellowship from the CNES (Centre National d'Études Spatiales) and the 292 European Research Council (ERC) remOcean project (grant agreement 246777).

294 Reference

295 Ardyna, M., M. Babin, M. Gosselin, E. Devred, L. Rainville, and J.-É. Tremblay (2014), Recent 296 Arctic Ocean sea-ice loss triggers novel fall phytoplankton blooms, Geophys. Res. Lett., 41(17), 297 6207-6212.

298 Arrigo, K. R., G. L. van Dijken, and S. Bushinsky (2008), Primary production in the Southern 299 Ocean, 1997-2006, J. Geophys. Res., 113(C8), C08004. 
Arrigo, K. R., G. L. van Dijken, and A. L. Strong (2015), Environmental controls of marine productivity hot spots around Antarctica, J. Geophys. Res., 120(8), 5545-5565.

302 Behrenfeld, M., and E. Boss (2014), Resurrecting the Ecological Underpinnings of Ocean

303 Plankton Blooms, Annu. Rev. Mar. Sci., 6, 167-194.

304 Boyd, P. W. (2002), Environmental factors controlling phytoplankton processes in the Southern 305 Ocean, J. Phycol., 38(5), 844-861.

Boyd, P. W., K. R. Arrigo, R. Strzepek, and G. L. van Dijken (2012), Mapping phytoplankton iron utilization: Insights into Southern Ocean supply mechanisms, J. Geophys. Res., 117(C6), 308 C06009.

309 Cassar, N., M. L. Bender, B. A. Barnett, S. Fan, W. J. Moxim, H. Levy, and B. Tilbrook (2007), 310 The Southern Ocean Biological Response to Aeolian Iron Deposition, Science, 317(5841), 10673111070.

D'Ortenzio, F., and M. Ribera d'Alcalà (2009), On the trophic regimes of the Mediterranean Sea: 313 a satellite analysis, Biogeosciences, 6(2), 139-148.

314 D'Ortenzio, F., D. Antoine, E. Martinez, and M. Ribera d'Alcalà (2012), Phenological changes of oceanic phytoplankton in the 1980s and 2000s as revealed by remotely sensed ocean-color 316 observations, Global Biogeochem. Cycles, 26(4), GB4003.

317 d'Ovidio, F., A. Della Penna, T. W. Trull, F. Nencioli, M. I. Pujol, M. H. Rio, Y. H. Park, C. 318 Cotté, M. Zhou, and S. Blain (2015), The biogeochemical structuring role of horizontal stirring: 319 Lagrangian perspectives on iron delivery downstream of the Kerguelen Plateau, Biogeosciences, 320 12(19), 5567-5581. energy input to the mesopelagic ecosystem from the seasonal mixed-layer pump, Nature Geosci, $9(11), 820-823$.

328 Edwards, M., and A. J. Richardson (2004), Impact of climate change on marine pelagic 329 phenology and trophic mismatch, Nature, 430(7002), 881-884. 
Fossheim, M., R. Primicerio, E. Johannesen, R. B. Ingvaldsen, M. M. Aschan, and A. V. Dolgov (2015), Recent warming leads to a rapid borealization of fish communities in the Arctic, Nature 332 Clim. Change, 5, 673-677.

333 Gille, S. T. (2014), Meridional displacement of the Antarctic Circumpolar Current, Phil. Trans. 334 R. Soc. A., 372(2019), 20130273.

335 Graham, R. M., A. M. De Boer, E. van Sebille, K. E. Kohfeld, and C. Schlosser (2015), Inferring 336 source regions and supply mechanisms of iron in the Southern Ocean from satellite chlorophyll 337 data, Deep Sea Research Part I: Oceanographic Research Papers, 104, 9-25.

338 Gregg, W. W., and K. L. Carder (1990), A simple spectral solar irradiance model for cloudless 339 maritime atmospheres, Limnol. Oceanogr., 35(8), 1657-1675.

340 Hartigan, J. A., and M. A. Wong (1979), Algorithm AS 136: A K-Means Clustering Algorithm, 341

Khatiwala, S., F. Primeau, and T. Hall (2009), Reconstruction of the history of anthropogenic J. Roy. Stat. Soc. C-App., 28(1), 100-108.

Hutchins, D. A., and P. W. Boyd (2016), Marine phytoplankton and the changing ocean iron cycle, Nature Clim. Change, 6(12), 1072-1079.

IOCCG (2009), Partition of the Ocean into Ecological Provinces: Role of Ocean-Colour Radiometry, International Ocean Colour Coordinating Group, Dartmouth, Canada.

Kim, Y. S., and A. H. Orsi (2014), On the Variability of Antarctic Circumpolar Current Fronts Inferred from 1992-2011 Altimetry, Journal of Physical Oceanography, 44(12), 3054-3071.

Lacour, L., H. Claustre, L. Prieur, and F. D'Ortenzio (2015), Phytoplankton biomass cycles in the North Atlantic subpolar gyre: a similar mechanism for two different blooms in the Labrador Sea, Geophys. Res. Lett., 2015 GL064540.

Landschützer, P., et al. (2015), The reinvigoration of the Southern Ocean carbon sink, Science, $349(6253), 1221-1224$. 000130 . 
361 Legendre, L., and F. Rassoulzadegan (1995), Plankton and nutrient dynamics in marine waters, 362 Ophelia, 41, 153-172.

363 Longhurst, A. (2007), Ecological Geography of the Sea (Second Edition), Academic Press, 364 Burlington.

365 Lund, R., and B. Li (2009), Revisiting Climate Region Definitions via Clustering, J. Climate, 366 22(7), 1787-1800.

367 Maritorena, S., O. H. F. d'Andon, A. Mangin, and D. A. Siegel (2010), Merged satellite ocean 368 color data products using a bio-optical model: Characteristics, benefits and issues, Remote Sens. 369 Environ., 114(8), 1791-1804.

370 Markus, T. (1999), Results from an ECMWF-SSM/I forced mixed layer model of the Southern 371 Ocean, J. Geophys. Res., 104(C7), 15603-15620.

372 Mayot, N., F. D'Ortenzio, M. Ribera d'Alcalà, H. Lavigne, and H. Claustre (2016), Interannual 373 variability of the Mediterranean trophic regimes from ocean color satellites, Biogeosciences, 374 13(6), 1901-1917.

375 Meijers, A. J. S., E. Shuckburgh, N. Bruneau, J.-B. Sallée, T. J. Bracegirdle, and Z. Wang 376 (2012), Representation of the Antarctic Circumpolar Current in the CMIP5 climate models and 377 future changes under warming scenarios, J. Geophys. Res., 117(C12), C12008.

378 Milligan, G., and M. Cooper (1985), An examination of procedures for determining the number 379 of clusters in a data set, Psychometrika, 50(2), 159-179.

380 Munro, D. R., N. S. Lovenduski, T. Takahashi, B. B. Stephens, T. Newberger, and C. Sweeney 381 (2015), Recent evidence for a strengthening CO2 sink in the Southern Ocean from carbonate 382 system measurements in the Drake Passage (2002-2015), Geophys. Res. Lett., 42(18), 3832015 GL065194.

384 O'Reilly, J., et al. (2000), SeaWiFS Postlaunch Calibration and Validation Analyses, Part 3Rep., 385 NASA Goddard Space Flight Center.

386 Pellichero, V., J. B. Sallée, S. Schmidtko, F. Roquet, and J. B. Charrassin (2016), The ocean 387 mixed-layer under Southern Ocean sea-ice: seasonal cycle and forcing, J. Geophys. Res. Oceans.

388 Polovina, J. J., E. A. Howell, and M. Abecassis (2008), Ocean's least productive waters are 389 expanding, Geophys. Res. Lett., 35(3), L03618.

390 Quéguiner, B. (2013), Iron fertilization and the structure of planktonic communities in high 391 nutrient regions of the Southern Ocean, Deep Sea Res. Pt. 2, 90(0), 43-54. 

Sallée, J. B., K. Speer, and R. Morrow (2008), Southern Ocean fronts and their variability to climate modes, J. Climate, 21(12), 3020-3039.

Sallée, J. B., K. G. Speer, and S. R. Rintoul (2010), Zonally asymmetric response of the Southern Ocean mixed-layer depth to the Southern Annular Mode, Nature Geosci, 3(4), 273-279.

Sanial, V., P. van Beek, B. Lansard, F. d'Ovidio, E. Kestenare, M. Souhaut, M. Zhou, and S. Blain (2014), Study of the phytoplankton plume dynamics off the Crozet Islands (Southern Ocean): A geochemical-physical coupled approach, J. Geophys. Res. Oceans, 119(4), 22272237.

Sanial, V., P. van Beek, B. Lansard, M. Souhaut, E. Kestenare, F. d'Ovidio, M. Zhou, and S. Blain (2015), Use of Ra isotopes to deduce rapid transfer of sediment-derived inputs off Kerguelen, Biogeosciences, 12(5), 1415-1430.

Shao, A. E., S. T. Gille, S. Mecking, and L. Thompson (2015), Properties of the Subantarctic Front and Polar Front from the skewness of sea level anomaly, J. Geophys. Res., 120(7), 51795193.

Simpkins, G. R., L. M. Ciasto, D. W. J. Thompson, and M. H. England (2012), Seasonal Relationships between Large-Scale Climate Variability and Antarctic Sea Ice Concentration, $J$. Climate, 25(16), 5451-5469.

Swart, S., S. Speich, I. J. Ansorge, and J. R. E. Lutjeharms (2010), An altimetry-based gravest empirical mode south of Africa: 1. Development and validation, J. Geophys. Res., 115(C03002), 2156-2202.

Tagliabue, A., L. Bopp, and O. Aumont (2009), Evaluating the importance of atmospheric and sedimentary iron sources to Southern Ocean biogeochemistry, Geophys. Res. Lett., 36(13), L13601.

Tagliabue, A., O. Aumont, and L. Bopp (2014a), The impact of different external sources of iron on the global carbon cycle, Geophys. Res. Lett., 41(3), 920-926.
Tagliabue, A., J.-B. Sallée, A. R. Bowie, M. Levy, S. Swart, and P. W. Boyd (2014b), Surfacewater iron supplies in the Southern Ocean sustained by deep winter mixing, Nature Geosci, 7(4), 314-320.

Tagliabue, A., A. R. Bowie, P. W. Boyd, K. N. Buck, K. S. Johnson, and M. A. Saito (2017), The integral role of iron in ocean biogeochemistry, Nature, 543(7643), 51-59. 
422 Venables, H. J., A. Clarke, and M. P. Meredith (2013), Wintertime controls on summer 423 stratification and productivity at the western Antarctic Peninsula, Limnol. Oceanogr., 58(3), $424 \quad 1035-1047$.

425 Zar, J. (2010), Biostatistical Analysis, 5th edition, Pearson Prentice Hall, New Jersey. 426 
429 Figure 1: Phytoplankton biomass, net primary production and phenology in the Southern

430 Ocean. Map showing the climatological (a) annual mean chlorophyll $a$ concentration $\left(\mathrm{mg} \mathrm{m}^{-3}\right)$,

431 (b) annual net primary production $\left(\mathrm{g} \mathrm{C} \mathrm{m}^{-2} \mathrm{~d}^{-1}\right)$, (c) the chlorophyll $a$ seasonality $\left(\mathrm{mg} \mathrm{m}^{-3}\right),(\mathrm{d})$

432 the timing of the bloom (week) maximum based on the GLOBcolour time series (1998-2014).

433 The climatological annual net primary production $\left(\mathrm{b} ; \mathrm{mg} \mathrm{C} \mathrm{m} \mathrm{d}^{-1}\right)$ was derived from the

434 adapted-SO NPP model of Arrigo et al. (2008). Frontal positions calculated from MADT

435 contours are shown for the STF (white), the SAF (red), the PF (yellow) and the SACCF (black).

437 Figure 2: Biogeography of the Southern Ocean. Spatial distribution (a) of the 7 bio-regions 438 (i.e. bio-regions 1 to 7 ) of the Southern Ocean obtained from the k-means analysis. The 439 normalized annual chlorophyll cycles (continuous lines) of the centers of the clusters $(b-h)$ 440 obtained from the k-means analysis are presented, as well as their respective standard deviation. 441 The absolute annual chlorophyll cycles (dashed lines) corresponding to the centers of the clusters $442(\mathrm{~b}-\mathrm{h})$ are also indicated.

444 Figure 3: Latitudinal repartition of the bio-regions and their respective biological 445 characteristics. Latitudinal proportion (a) of the different bio-regions. Box plots of the bio446 regions ( 1 to $7 ; \mathrm{x}$ axis) against (b) annual mean chlorophyll $a$ concentration $\left(\mathrm{mg} \mathrm{m}^{-3}\right)$, (c) the 447 chlorophyll a seasonality $\left(\mathrm{mg} \mathrm{m}^{-3}\right)$, (d) the timing of the bloom maximum (month; y axis). The 448 line in the middle of each box represents the region median. The top and bottom limits of each 449 box are the 25 th and 75 th percentiles, respectively. The lines extending above and below each 
450 box, i.e., whiskers, represent the full range of non-outlier observations for each variable beyond 451 the quartile range. The results of the Kruskal-Wallis $\mathrm{H}$ test are shown in figures (b) through (d), 452 and depict regions with statistically significant differences between the climatological input 453 variables at the $95 \%$ level $(\mathrm{p}<0.05)$. The codes of the test significance are as follow $:: \mathrm{p}<0.05$, $454 *$ : $<<0.01, * *: \mathrm{p}<0.001$ and $* * *: \mathrm{p}<0.0001$

456 Figure 4: Environmental control of phytoplankton biomass and phenology in the Southern

457 Ocean. Double boxplot (a) of the maximum bloom timing (weeks) versus the annual mean PAR $458\left(\mathrm{E} \mathrm{m} \mathrm{y}^{-1}\right)$ of the different bio-regions. The top/right and bottom/left limits of each box are the 45925 th and 75 th percentiles, respectively. The numbers in each box are located at the median of 460 both maximum bloom timing and annual mean PAR. Barplot (b) of the mean annual 461 chlorophyll $a$ concentration according (1) the shallow areas ( $<500 \mathrm{~m}$; red), (2) areas where iron 462 delivery downstream take place (\%; percent of iron remaining in a water parcel after scavenging 463 in respect to its initial concentration acquired in shallow areas; red to blue), (3) areas 464 characterized by a seasonal sea-ice cover (grey) and (4) areas where variations in the annual 465 maximum MLD are analyzed (white). See the map (c) delineating the distinct areas listed just 466 above. 
Figure 1. 

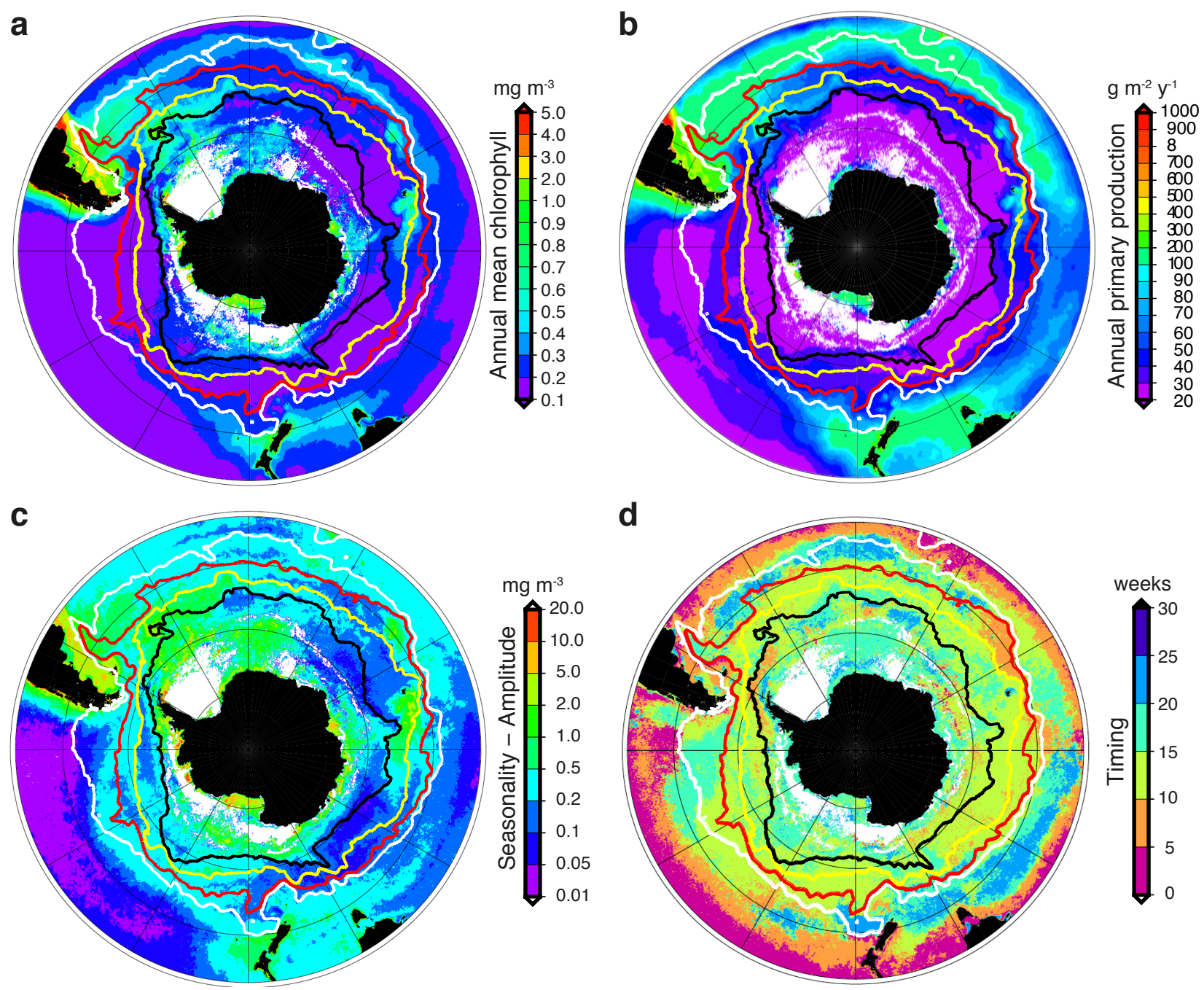
Figure 2. 
Figure 3. 


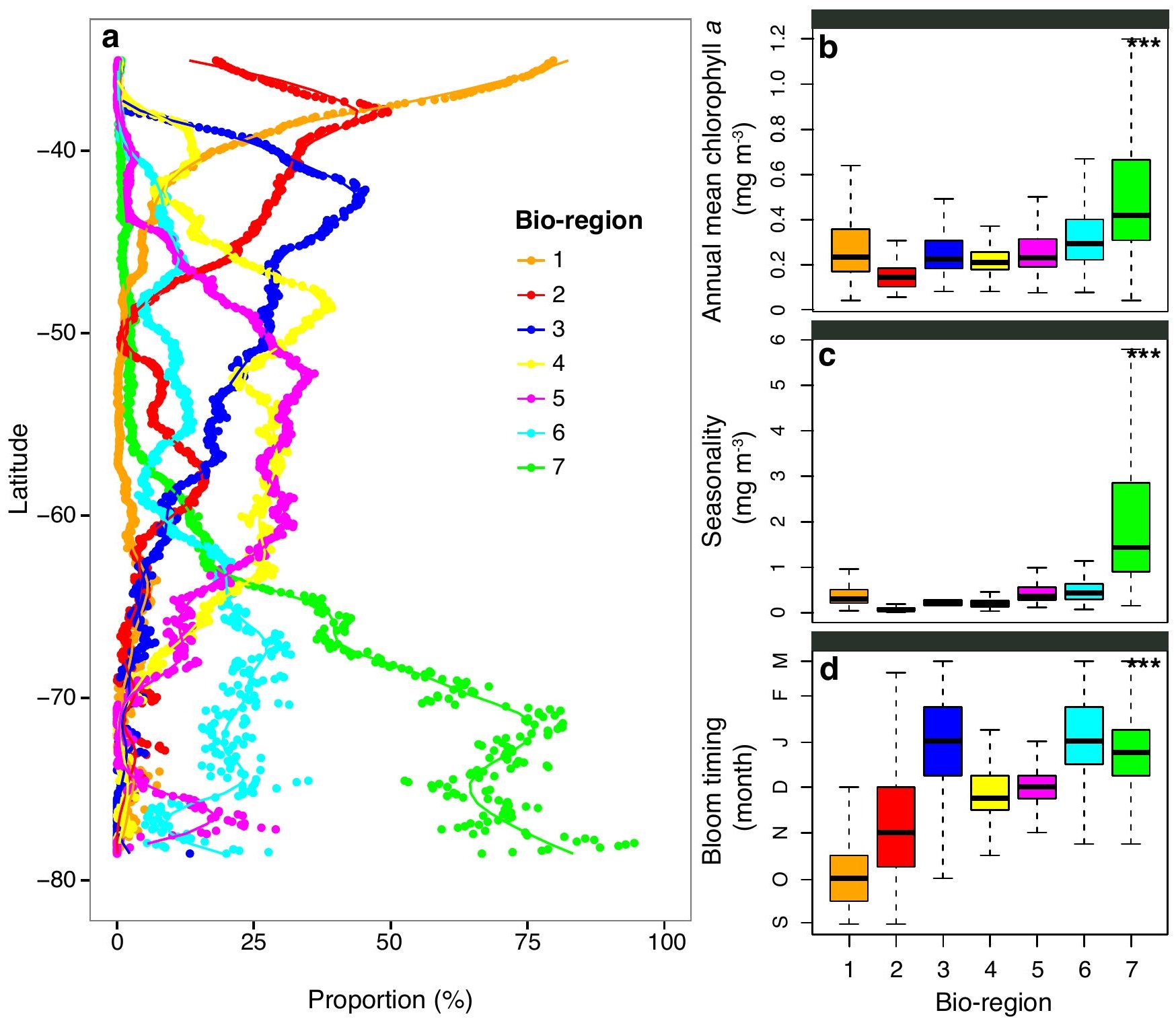


Figure 4. 


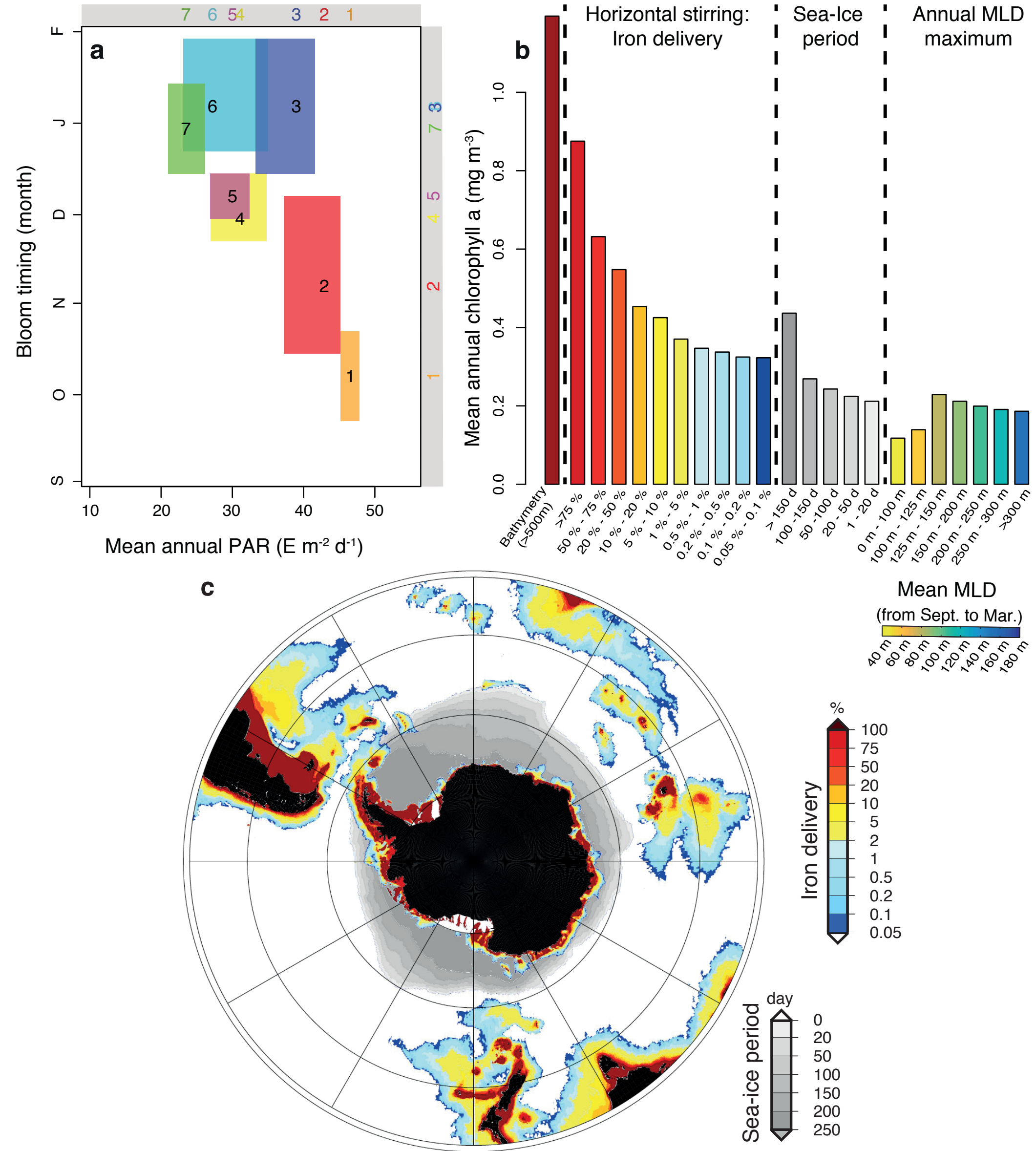

